\title{
A comprehensive approach to the development of thinking skills
}

\author{
G. J. Rossouw \\ Department of Philosophy \\ Rand Afrikaans University \\ JOHANNESBURG
}

\author{
J.C. Lamprecht \\ Faculty of Education \\ Rand Afrikaans University \\ JOHANNESBURG
}

\begin{abstract}
A comprehensive approach to the development of thinking skills

The development of independent and innovative thinking entails much more than merely the acquisition of a series of thinking skills. A comprehensive approach based upon inter-disciplinary cooperation between, among others, the disciplines of philosophy, education and pscychology is needed. In such a comprehensive approach to the development of thinking skills the following factors that have a bearing on the acquisition of thinking skills should be addressed:
\end{abstract}

* The cultivation of a positive disposition towards the development of thinking.

* The creation of conditions conducive to the development of thinking.

* The cultivation of virtues that will dispose a person towards good thinking.

* An understanding of what good thinking entails.

* The teaching and assessment of thinking skills.

In this article, these various factors and their bearing on the development of thinking skills are explored. A general theoretical framework for the development of thinking skills is proposed that can and should be translated to specific domains of knowledge or to specific human enterprises. 


\section{Introduction}

The White Paper on education produced by the government of national unity in South Africa stressed the importance of the development of the ability to think independently and innovatively. South Africa is not unique in this regard, because this need has also been recognised in many other countries. The legitimacy of this need has already been argued convincingly, and will therefore be taken for granted in this article (cf. Paul, 1992:13; Clur, 1994:37). The focus of this article will instead be on how the ability to think independently and innovately should be approached.

The approach that will be suggested in this article departs sharply from the notion that the ability to think independently and innovately can be infused merely by teaching students a series of thinking skills. It will rather be argued that the development of such a thinking ability requires a comprehensive approach to the development of thinking that invites inter-disciplinary cooperation between, among others, the disciplines of philosophy, education and psychology. Within such a comprehensive approach the following factors that have a bearing on the acquisition of thinking skills should be addressed:

* The cultivation of a positive disposition towards the development of thinking.

* The creation of conditions conducive to the development of thinking.

* The cultivation of virtues that will dispose a person towards good thinking.

* An understanding of what good thinking entails.

* The teaching and assessment of thinking skills.

This comprehensive approach that will be suggested provides a general theoretical framework that can and should be translated to specific domains of knowledge or to specific human enterprises. (For more on the debate between general and domain-specific thinking skills and the problem of transfer see Talaska, 1992:xiii-xxvi; Ennis, 1992:14-15; Siegel, 1992:102; Perkins, 1986:8-9.)

The term thinking skills will be used in this article to refer to both critical and creative thinking skills. This will be demonstrated in section four of this paper where our understanding of the process of thinking will be revealed. Suffice to say at this point that the tension often alleged to exist between critical and creative thinking is regarded as a false and unnecessary tension. (For more on this debate see De Bono, 1990:37-43; Paul, 1992:10, 17-18; Bailin, 1987:25; Gilhooley, 1988:174.) 
G.J. Rossouw \& J.C. Lamprecht

Each of the dimensions that contribute towards the comprehensive development of thinking skills will now be discussed.

\section{The cultivation of a positive disposition towards the development of thinking skills}

People tend to invest their time, talents and money only in those things that they consider worthwhile. This truism also applies to the acquisition of thinking skills. Unless one deems thinking skills a valuable asset, chances are very slim that one will invest the effort required for the acquisition of thinking skills. The process of the development of thinking skills can therefore only get on track once a strong conviction about the importance of thinking skills has been established (Rossouw, 1994:4-6).

There are many ways in which the case for the importance of thinking skills can be argued. These reasons may have to do either with ourselves, our interaction with others, our education, our jobs, and many other things (cf. Kaplan, 1991:363; Maker, 1982:18-19; Siegel, 1985:71-72). Rather than compiling an impressively long list of reasons that apply to the different dimensions of our lives, an alternative strategy will be followed to argue the case for the importance of thinking skills. This alternative consists of a certain quality of life. It is argued that that quality of life is not attainable without well-developed thinking skills.

The quality of life that we want to portray as an ideal is a life characterised by independence, interdependence, innovation and security. These four characteristics are mostly in tension with one another. On the one hand we continually strive towards self-determination, but at the same time we also wish to stay in community with our fellow beings. This can be described as a tension between independence and interdependency. On the other hand we are also torn between a need for innovation, but at the same time we wish to enjoy security. The tension created by the two poles of each of these polarities can be resolved by opting for one of the poles. This would, however, be a grave mistake in any dimension of our lives. The ideal is to keep all four the mentioned poles in balance with one another. None of these four poles can, however, be achieved without good thinking. It is impossible to be independent unless one is willing to think through issues and problems on your own. It is impossible to be interdependent, unless one is willing to think in terms of others and in terms of their ideas. It is impossible to be innovative, unless one is willing to think critically about existing ideas and to experiment with new ideas. It is equally impossible to enjoy security unless one is able to justify the thinking that grounds one's current position.

Koers 60(4) 1995:521-539 
Consider the case of a scientist to illustrate the point. On the one hand we expect good scientists to be able to think independently and to take a stand on the issues that they are confronted with. On the other hand we also expect good scientists to interact with the fellow members of the scientific community and to be open to new ideas. In the same way the good scientist is expected to be innovative and to challenge existing ideas, but at the same time we expect the good scientist to justify his or her findings - that is, the scientist is expected to explain new ideas in terms that are familiar and trusted by the scientific community in which the scientist operates. The same also holds true for the student, the friend, the politician, etc.

This line of thought illustrates that the ideal of being both independent and interdependent and of being both innovative and secure is attainable only when one has the necessary thinking skills. The extent to which one will be able to realise this ideal depends on the sophistication of one's thinking skills. In short then, should one aspire towards the ideal of being at the same time independent and interdependent, and innovative and secure in the different domains of one's life, one should commit oneself to the development of those thinking skills that will enable one to achieve this ideal.

This argument based upon a certain desirable quality of life is just one way of convincing other persons of the importance of acquiring proper thinking skills. Many other arguments can be used depending on who the person or group is that one wishes to persuade. The important point, however, is that one cannot commence with the teaching of thinking skills, unless students are motivated to develop their thinking skills.

\section{The creation of conditions conducive to the develop- ment of thinking skills}

The development of thinking skills can never be considered in isolation from the specific context in which individuals find themselves. Within this context there are certain personal (internal) and environmental (external) factors which should be taken into consideration in the process of the development of thinking. These factors can, on the one hand, be enabling but on the other hand have a disabling effect on the development of critical and creative thinking skills, depending on how a person reacts thereto. Stress can, for example, be enabling when it creates moderate dissonance and gives rise to a motivation to think critically and creatively. However, when stress gives rise to excessive dissonance and causes anxiety, it could inhibit the development of thinking skills. In the same way, every specific factor which is discussed in this section has an enabling and a disabling side. It is, therefore, important to identify factors which are positively or negatively related to thinking skills and 
to indicate how such disabling factors should be managed and how enabling factors should maximally be utilised.

The following five broad categories of factors can be distinguished, namely intra-personal, physiological, interpersonal, cultural and environmental factors. Intra-personal and physiological factors refer to persons as individuals and to what makes them unique, while interpersonal factors refer to the interaction of the individuals with other persons in their environment. Cultural and environmental factors, on the other hand, relate to the specific context in which individuals find themselves.

\subsection{Intra-personal factors}

In addition to stress, which has already been discussed in the preceding section, a number of specific factors are distinguished. These factors relate to the psychological functioning of persons (cf. Paul, 1993:95; West \& Farr, 1990:217-221; Evans, 1991:38-39). As already indicated, each of these factors could be disabling or enabling in respect of creative and critical thinking.

\section{- Motivation}

Motivation refers to a force within a person which gives rise to certain actions. These actions may arise as a result of an intrinsic motivation to achieve a specific goal, or they may be forced actions which arise merely as a result of extrinsic pressure. The development of critical and creative thinking skills is closely linked to intrinsic motivation because it is closely related to concepts such as perseverance, determination of own standards and the acceptance of responsibility.

\section{- Self-concept}

Self-concept refers to the determination of individuals' self-esteem and it could take on a positive or negative dimension depending on the specific context within which they find themselves. This experience of the self is, in turn, closely related to success or failure orientation. The self-confidence which is thus generated could be decisive for the development of critical and creative thinking skills, because it can, inter alia, determine the degree of selfassertiveness and self-responsibility of a person.

\section{- $\quad$ Personality}

Personality refers to a variety of characteristic features of people as they are displayed in their interaction with themselves and with others. These mental, social and moral features determine all actions, including the thinking process. Specific personality features which may influence the development of critical and creative thinking include, inter alia, variables such as emotional stability, 
A comprehensive approach to the development of thinking skills

opportunism, self-assurance, individualism and discipline. Each of these variables may contribute to the enabling or disabling of the thinking process.

\section{- Values}

Values refer to what is important to a person - that which makes life meaningful and humane. People determine their priorities on the basis of these values. The following groups of values are important within the context of thinking development: Self-realisation values, which include self-respect, independence and idealism, interaction values, which include respect, empathy and co-operation, work values, which include honesty, fairness and loyalty.

\subsection{Physiological factors}

Apart from certain psychological factors, there are certain enabling and disabling physiological factors present in a person which should also be taken into consideration in the development of thinking skills.

\section{- $\quad$ Functioning of the brain}

Knowledge of the functioning of the brain is essential in order to plan thinking development strategies, especially in younger children and adolescents (Buzan, 1993:34-35). It is, firstly, necessary to take cognisance of Piaget's stages (1972) of cognitive development, viz. the sensory-motor, pre-operational, concrete and formal stages. Besides Piaget, Kohlberg's stages (1984) of moral reasoning are also important within the context of thinking development. Like Piaget, Kohlberg indicated at what stage children and adults are ready to make certain kinds of moral decisions. Teaching of thinking skills should thus be in accordance with the level of brain development of the child.

Secondly, cognisance must be taken of the child's intellectual development. (It is not simply a purely cognitive process since, according to Feuerstein (1980) and Vygotsky (1978), the environment and socio-cultural experiences have a decisive influence on cognitive development.)

Thirdly, cognisance must be taken of the functioning of the left- and right-brain and the interaction between the two, which could have a decisive influence on strategies for the development of critical and creative thinking skills.

\section{- Physical functioning and health}

The functioning of the human body has a definite effect on the functioning of the mind. When a person is tired, suffers from a headache or is sick or hungry, it can have a negative effect on the acquiring of thinking skills. Physical fitness, on the other hand, can contribute to an increase in mental awareness. 
G.J. Rossouw \& J.C. Lamprecht

It cannot, however, simply be assumed that the defective functioning of the body or part of the body is necessarily a disabling factor. A blind person can, for example, as a result of his/her blindness compensate by developing other senses which could result in the sharpening of thinking skills.

Because physical care refers to a person's most basic needs, according to Maslow (1970), it is necessary to have knowledge thereof and to establish to what extent it is an enabling or disabling factor in the development of the mind.

\subsection{Interpersonal factors}

Interpersonal factors refer to the interaction or communication of a person with other people. In this interaction a variety of enabling or disabling interventions may occur which could have an effect on the development of critical and creative thinking.

\section{- Personality styles}

Every person has a personality with unique characteristics. Merrill and Reed (1981) uses a classification where a distinction is made between dominant, socialising, analytical and accommodative personality styles. The question which arises in this regard is how persons with diverse personality styles react towards one another and how this could affect the thinking process in an enabling or disabling manner. Persons with a predominantly analytical personality style can, for example, be dispowered in their thinking by persons with more socialising personality styles. They can be manipulated and dominated to such an extent by persons with a socialising personality style that they become uncertain to some degree and thus they are dispowered in respect of thinking skills. The same principle also applies to persons with more accommodative personality styles who could, once again, be dispowered by persons with more dominant personality styles.

\section{- Leadership and management styles}

As far as leadership and management styles are concerned, the autocratic, free reign and democratic styles can be distinguished. Each of these styles has an enabling and a disabling side in relation to thinking skills. In emergency situations an autocratic style is, for example, indispensable because quick thinking actions must be undertaken. An autocratic style can, however, make it impossible for others to take their own stands. The same principle also applies in the case of the other two personality styles (Charlton, 1993:24-26).

Within the concept of leadership and management styles, a distinction can also be made between person- and task-orientation. The former management style places emphasis on healthy human relations, while the latter management style 
A comprehensive approach to the development of thinking skills

emphasises the execution of a task or assignment. A person-orientated management style could be disabling when excessive emphasis is placed on a too accommodative interpersonal communication relationship where no real demands are made on others to think rigorously. A person-orientated management style may, on the other hand, have an enabling influence when a person receives individual attention to such a degree that he/she becomes motivated to improve his/her thinking skills considerably. In a similar way, and depending on the specific circumstances, a task-orientated management style could also be enabling or disabling with regard to the development of critical and creative thinking skills.

\subsection{Cultural factors}

This section focuses on the individual and the context(s) within which persons may find themselves. These contexts could include (1) a group of people or a community; (2) a workplace which could be an organisation, school or business; (3) a people, nation or ethnic cultural group. In each of these cultural groups there are certain values present which could have an enabling or disabling impact on the development of thinking. In other words, the values of a certain context could be inhibiting or conducive to thinking development (Gamache \& Kuhn, 1989:18-21; Charlton, 1993:77-83; West \& Farr, 1990:265-269). Values which are involved here include, among others, confidence, freedom, authoritarianism, invitation to participate, loyalty and conformism. Only two of these values will be briefly discussed by way of example.

\section{- Confídence and freedom}

The concept freedom implies confidence. Freedom creates the space for innovative thinking and vigorous investigation of the unknown. The experience of freedom can lead to self-confidence, with the accompanying conviction that "I am able to think independently".

Freedom can, however, be disabling when an easy-going whatever-will-be-willbe attitude is developed and when no demands are made in respect of the development of thinking. Freedom can, however, also be disabling when one feels unsafe because no margins have been set for one. In this case, one could easily be too careful to take even the smallest risk in thinking. On the other hand, freedom could also tempt one to overestimate oneself and to take risks which one cannot handle.

\section{- Authoritarianism}

A value system which is authoritarian discourages independent thinking and will be detrimental to the development of thinking skills. This could lead to a 
G.J. Rossouw \& J.C. Lamprecht

feeling of inadequacy to form an own opinion. Such persons could become dependent upon others to think on their behalf. On the other hand, the feeling of being a figure of authority could contribute to the experience of authority. The feeling of responsibility which arises from this could provide the necessary stimulus to want to know more about a certain subject and this, in turn, could stimulate critical and creative thinking.

\subsection{Environmental factors}

In conclusion, it is important to be aware of the direct environmental factors which could have an impact on the development of thinking skills (Buzan, 1993:109-110). The following environmental factors could be enabling or disabling for the development of thinking skills.

\section{- The location or site of the person's workplace}

The question which must be answered in this regard is: are the physical conditions in line with the person's needs and does the environment provide sufficient stimulation for critical and creative thinking?

\section{- Illumination}

Is the illumination adequate for the person to function optimally?

\section{- $\quad$ Noise}

Are there noises that inhibit or stimulate one? Noise (for example, the ringing of the telephone or human interruption) could hamper concentration. On the other hand, music sometimes has a stimulating effect, particularly on creative thinking.

\section{- Infrastructure}

It is important to establish an effective infrastructure to enable one to give one's undivided attention to one's task.

\section{The cultivation of virtues that will dispose a person towards good thinking}

In this section specific attention will be given to the development of virtues that a good thinker should display. Virtues of thinking can be defined as a specific inclination towards thinking that a person should possess in order to think as clearly, justifiably, fluently and reflectively as possible. Without such an inclination one could easily become trapped in an attitude of apathy which could give rise to sloppy and superficial thinking. The ultimate goal for these virtues is to be inherent in a person and that they must form part of that person's "default thinking mode". 
A comprehensive approach to the development of thinking skills

Aristotle (1976:91-110) argued that virtues have two important effects. Firstly, one is prevented from indulging in undesirable behaviour, and secondly, one is satisfied when doing the correct things. He furthermore argued that virtues can only be acquired by practice and habituation. Aristotle's thought on moral virtues can also be applied to the virtues of thinking. The virtues that should become part of the mindset of the disciplined thinker should prompt the thinker to avoid the pitfalls and pleasures of bad thinking, while experiencing satisfaction and a sense of achievement through good thought. Without these virtues of thinking, thinking skills can be put to cold-blooded use. They can be used to justify ego- or sociocentric interests or to promote and justify immoral behaviour (Paul, 1982:5; Reeder, 1984:19; Martin, 1992:171-173).

Whilst certain virtues of thinking could be inherent, others need to be cultivated. This process of cultivation of virtues, however, implies a fairly permanent change in a person's attitude. These virtues are then experienced as intrinsic aspirations which direct a person's thinking. A virtue which has thus become an integral part of a person's frame of reference eventually becomes a habit which results in spontaneous behaviour. A person then unconsciously gets into the habit of thinking properly.

The following virtues of thinking can be regarded as essential within the context of the development of critical and creative thinking skills (Paul, 1992:55, 85 \& 258-262; Paul, 1993:535; Rossouw, 1994:6-9; Sternberg, 1992:122-127; Adair, 1990:83; Collins \& Mangieri, 1992:19).

\section{- Calculative}

There is no doubt that one of the virtues of thinking is the willingness to think analytically, to form syntheses and to evaluate. This implies that the person must be able to think questioningly, to notice a wide span of relevance which is then integrated and evaluated.

\section{- Courage}

To be courageous implies that a person is prepared to challenge existing ideas in a search for more appropriate and new alternatives. Such a person tends to take risks and does not feel threatened easily.

\section{- Willingness to experiment}

Experimenting with new ideas assumes that a person is prepared to take the initiative and is curious as to what might happen. Curiosity refers to a desire to discover, learn and know more. It presupposes an investigative attitude and a determination to take the initiative and to find out more. 
G.J. Rossouw \& J.C. Lamprecht

\section{- Independence}

Independence refers to one's willingness to accept responsibility for one's thinking actions. One then becomes inclined to solve problems by oneself and not to depend on external solutions. This virtue refers to an internal locus of control - which implies that one has control over one's thinking processes.

\section{- Self-evaluation}

Self-evaluation assumes that one is able and willing to reflect meta-cognitively on one's own thinking. It implies that one must be able to stand back while reflecting on one's own thinking. One must also be willing to notice one's own thinking mistakes and to rectify them. Any unfounded assumptions, erroneous presuppositions and unwarranted conclusions must, for example, be revised.

\section{- Open, fair and emotionally controlled}

To be unprejudiced implies that one should be able to listen to the views of others with an open mind and to evaluate it fairly. It involves a receptive attitude towards the views of others about an issue - even if they differ vastly from one's own views. It also implies willingness to give others a fair chance to state their case.

To think rationally means to be emotionally controlled in one's own thinking and to be able to separate reason from emotion.

\section{- Perseverance}

Critical and creative thinking assumes the willingness to spend time and to persevere in the search for solutions to complex problems. It is an ongoing combination of analysing, synthesising, imagining, evaluating and revising. It requires an attitude of commitment and the perseverance to pursue an issue especially where there are a multitude of possible solutions.

\section{An understanding of what good thinking entails}

A sharp distinction should be drawn between (1) the process of thinking, (2) criteria for good thinking, and (3) thinking skills. The process of thinking refers to the cognitive operations that have to be performed when one is thinking about an issue or problem (cf. Paul, 1992:28-31, Meehan, 1988:214226, Rossouw, 1990:57-58). Criteria for good thinking refers to a certain standard that has to be met when performing these cognitive operations. Thinking skills refer to the cognitive abilities that one could develop in order to perform the mentioned cognitive operations well and in accordance with the said criteria. This already implies that the teaching of thinking skills does not make much sense unless one understands where the respective thinking skills 
A comprehensive approach to the development of thinking skills

fit into the process of thinking and what the criteria are that have to be satisfied in the process of thinking.

\subsection{The process of thinking}

Thinking about any subject, issue or problem, demands performing some or all of the following cognitive operations:

- Identifying the problem

Thinking mostly starts when one is confronted with a problem or question which invites or compels one to think towards a solution for the problem.

- Creating a strategy for problem solution

In order to solve the problem a strategy is needed that will provide one with the information needed to solve the problem.

- Collecting information

The strategy for problem solution compels one to gather that information that might contribute towards the solution of the problem.

- Processing information

The gathered information needs to be elaborated into meaningful units in order to evaluate their possible contribution towards the solution of the problem.

- Formulating a conclusion

A solution to the problem is formulated in such a way that the solution is supported by the processed information.

- Implementing the conclusion

The conclusion often compels one to adapt or change one's circumstances in order to be able to accommodate the conclusion.

- Systematising the conclusion

The conclusion also has to be harmonised with the frame of reference in which one is working.

- Evaluating the conclusion

The extent to which the proposed solution is successful in solving the problem in a way that is compatible with one's circumstances and frame of reference has to be determined.

The sequence does not have to follow in the order described here. Creativity is often stimulated by an intentional disruption of the sequence described above. 
G.J. Rossouw \& J.C. Lamprecht

\subsection{Criteria for good thinking}

The ability to perform these operations does not make one a good thinker. Both excellent and poor thinkers are able to perform these (or at least some of these) operations, for example, both excellent and poor thinkers can perform the operation needed to formulate a conclusion. The difference between them is the quality of the result that the respective cognitive operations render. What distinguishes good thinkers from poor thinkers, is their ability to perform these operations self-consciously and according to certain criteria (cf. Paul, 1992:153164). One can distinguish both general criteria that apply to all eight of the cognitive operations, and more specific criteria that apply only to specific operations. Only the general criteria to which each of these operations has to comply will be identified here.

There are especially four criteria that good thinkers have to satisfy when performing any of the above cognitive operations.

- Clarity: The meaning of what is stated should be as clear and distinct as possible. Vagueness and ambiguity should thus be eliminated as far as possible in each cognitive process.

- Justifiability: What is stated should be justified. That is, appropriate grounds or reasons for doing, or saying something should be provided. One should thus be able to give a logically coherent explanation for what one is doing or saying at any given point in the process of thinking.

- Flexibility: One should be able to perform each of the operations in a variety of ways. In this respect one should distinguish between conventional ways and unconventional ways of performing each of the cognitive operations. Conventional ways of performing these operations are often referred to as critical or convergent thinking, while unconventional ways are referred to as creative or divergent thinking.

- Reflectivity: One should think about one's thinking. Good thinkers are both willing and able to review their own thinking in order to determine if it complies to the above-mentioned process and criteria. This ability to reflect on their own thinking enables good thinkers to improve their thinking.

\subsection{Thinking skills}

Thinking skills are those acquired abilities or intellectual tactics (Perkins, 1986:5) that enable one to perform the different cognitive operations in the thinking process in a manner that will satisfy the criteria for good thinking. The list of thinking skills that can be identified is not only impressively long, 
A comprehensive approach to the development of thinking skills

but it also differs from domain to domain. The skills needed for collecting information in the domain of philosophy differ markedly from the skills needed for collecting information in the domain of nuclear physics, for example. We therefore would not even attempt to compile a comprehensive list of all possible thinking skills that can be listed under each cognitive operation. We will only provide a brief indication of the thinking skills that are relevant for performing just one of the steps in the thinking process, namely the cognitive operation of identifying a problem. The kind of abilities that have to be acquired to perform this operation in accordance with the criteria for good thinking are:

- The ability to distinguish different kinds of problems or questions (for example, distinguishing closed questions from open questions, or moral problems from practical problems).

- The ability to identify the assumptions underlying problems.

- The ability to identify the intellectual context of problems (for example, what is the frame of reference or the paradigm in terms of which a problem is formulated).

- The ability to identify the historical context of problems (for example, what are the series of events and variables that contributed towards the development of the problem).

- The ability to define a problem in such a way that a viable problem-solving strategy can be devised for it (for example, not to formulate the problem either too narrowly or too broadly, because in both cases the process will result in an unsatisfactory conclusion or solution).

\section{The teaching and assessment of thinking skills}

The four factors discussed till now need to be integrated into a comprehensive approach when one attempts to teach to attain the improvement of thinking.

\subsection{Objective}

The process of teaching for improved thinking starts with the identification of the problem that one wishes to address. It can hardly be overemphasised that one cannot teach with the aim of improving thinking in general. One should identify very clearly what the specific cognitive operation or operations are in the thinking process that one wishes to focus on and what the relevant thinking skills are that one wishes to develop with regard to that specific cognitive operation. 
G.J. Rossouw \& J.C. Lamprecht

Only then can one decide on a strategy for teaching those thinking skills that one had opted for. Such a strategy should make provision for mainly three elements: climate, content, and evaluation.

\subsection{Climate}

In creating a climate conducive to the developing of thinking one could start by identifying the disabling factors that might hinder the learning process. Any of the five factors discussed in the second section of this paper (the creation of conditions conducive to the development of thinking) that might have a negative impact, should be eliminated as far as possible. Eliminating negative influences is not enough. One should go further and also create conditions that will invite and stimulate the development of thinking. Once again one should look at the five categories of factors that might influence the development of thinking and determine how these factors can be manipulated in order to create a situation most conducive for the development of thinking.

\subsection{Content}

Within this climate conducive to the development of thinking, one should develop a program that makes provision for some, but preferably all, of the following:

\section{- Positive disposition towards development of thinking}

It was argued in part 1 of this article (the cultivation of a positive disposition towards the development of thinking) that it is very hard to develop a person's thinking ability, unless the person is convinced that an improved thinking ability is an important asset. One should thus find a way in which prospective students can be motivated to invest their energy and time in the development of their thinking ability. The key to success in this respect is to focus on the kind of considerations that matters most to the persons involved. This implies that one should have access to a variety of strategies and considerations that can convince persons of the importance of a good thinking ability. In this regard the insights gained from theories on motivation can be most helpful.

\section{- Knowledge about thinking}

The program should furthermore make provision for learning about what good thinking entails. Students can easily loose track if they do not have at least a broad notion of what the cognitive operations involved in thinking are and what the standards are to which good thinking should comply. If these two dimensions are neglected, the students will hardly be in a position to reflect meta-cognitively on their own thinking - which of course is a pre-condition for the development of their thinking ability. 
A comprehensive approach to the development of thinking skills

\section{- Thinking skills}

The program should further consist of both clear definitions of the thinking skills that one has selected to teach and exercises in practising these thinking skills. It is pretty hard to acquire these thinking skills without trying one's hand to them. The program should thus make provision for doing such exercises, but also for feedback and preferably further exercises in the light of the feedback.

\section{- Virtues of good thinkers}

Ideally the program should also cater for the cultivation of certain virtues in the student. These virtues can only be developed by means of an intentional effort to bring about a change in attitude in a person. Changing attitudes is, however, a complex issue. It can only happen when a person experiences a strong feeling of dissonance, which leads to the desire to acquire certain thinking skills. A change of attitude does not happen overnight - opportunities have to be created to cultivate these virtues. A variety of techniques can be used to effect the desired change in attitude, like role-play, group discussions and identification models. Sufficient feed-back as well as direct support is indispensable.

\subsection{Evaluation}

Unless one builds in a variety of evaluation procedures whilst teaching for improved thinking, one might be wasting a lot of time and energy. There are mainly three kinds of things that have to be assessed. First, the competence of students at the beginning of the intervention should be assessed. One should determine what their current thinking competency is in order to set the goals that one wishes to achieve. Second, one should determine their competency in thinking during as well as at the end of the program. Only when this has been done will one be in a position to give students feedback on their progress and will one be able to determine the success of the intervention. A variety of assessment tools are needed in order to assess the different thinking skills involved in the process of thinking. Third, besides the assessment of thinking skills one should also determine whether one has been successful with one's interventions with regard to the other dimensions that have an impact on the development of thinking, such as:

* Students' disposition towards thinking.

* The conduciveness of the climate for the development of thinking.

* The students' virtues of thinking.

The evaluation of these three just mentioned dimensions poses a challenge that most probably exceeds the competence of any singular school teacher, university professor or manager. This just re-emphasises the importance of 
G.J. Rossouw \& J.C. Lamprecht

interdisciplinary co-operation, interdisciplinary research and of the sharing of experiences.

\section{Conclusion}

The 1994 White Paper on education states that "the curriculum and teaching methods should encourage independent and critical thought, the capacity to question, enquire and reason, to weigh evidence and form judgments, to achieve understanding, and to recognise the provisional and incomplete nature of most human knowledge" (p. 12). This challenge posed by the White Paper invites hard and innovative thinking about how this goal can be achieved. In this article it was argued that a mere focus on teaching-specific thinking skills is not sufficient. A comprehensive approach such as displayed in this article is needed. Such an approach demands that the isolation between the various academic disciplines should be bridged in order to develop an interdisciplinary approach to the development of thinking skills.

Many issues surrounding the development of thinking skills still need further exploration. Issues such as the tension between general thinking skills and domain-specific thinking skills, the question about transfer of thinking skills from one domain to another, as well as various other questions surrounding the teaching of thinking skills in a classroom need to be addressed.

\section{Bibliography}

ADAIR, J. 1990. The Art of Creative Thinking. Newlands : Talbot Adair Press.

ARISTOTLE. 1976. The Nicomachean Ethics. London : Penguin Books.

BAILIN, S. 1987. Critical and Creative Thinking. Informal Logic, 9(1):2330.

BUZAN, T. 1993. The Mind Map Book. New York : BCA.

CHARLTON, G. 1993. Leadership: The Human Race. Kenwyn : Juta \& Company.

COLLINS, C. \& MANGIERI, J.N. 1992. Teaching Thinking: An Agenda for the Twenty-First Century. New Jersey : Lawrence Erlbaum Associates.

CLUR, B. 1994. Good Thinking: The Missing Link. People Dynamics, 3639 , Oct.

DE BONO, E. 1990. Lateral Thinking. London : Penguin Books.

ENNIS, R.H. 1992. Conflicting Views on Teaching Critical Reasoning. (In Talaska R.A., ed. Critical Reasoning in Contemporary Culture. Albany : State University of New York Press. p. 5-27.)

EVANS, J.R. 1991. Creative Thinking in the Decision and Management Sciences. Cincinnati : South Western Publishing Company. 
A comprehensive approach to the development of thinking skills

FEUERSTEIN, R. 1980. Instrumental Enrichment: An Intervention Program for Cognitive Modifiability. Baltimore : University Park Press.

GAMACHE, R.D. \& KUHN, R.L. 1989. The Creativity Infusion. New York : Harper \& Row.

GILHOOLEY, K.J. 1988. Thinking: Directive, Undirective and Creative. London : Academic Press.

KAPLAN, L.D. 1991. Teaching Intellectual Autonomy: The Failure of the Critical Thinking Movement. Educational Theory, 41(4):361-370.

KOHLBERG, L. 1984. Essays on Moral Development. San Francisco : Harper \& Row.

MAKER, W. 1982. Teaching Informal Logic as Emancipatory Activity. Informal Logic Newsletter:17-20, Dec.

MARTIN, J.R. 1992. Critical Thinking for a Humane World. (In Norris, S.P., ed. The Generalizability of Critical Thinking. London : Teachers College Press. p. 163-180.)

MASLOW A.H. 1970. Self-Concept and Personality. New York : Harper \& Row.

MEEHAN, E.J. 1988. The Thinking Game. Chatham : Chatham House Publishers.

MERRILL, D.W. \& REED R.H. 1981. Personal Style and Effective Performance. Radnor : Chilton Books.

PAUL, R. 1982. Teaching Critical Thinking in the "Strong" Sense: a Focus on Self-Deception, World Views, and a Dialectical Mode of Analysis. Informal Logic Newsletter, 4(2):2-7.

PAUL, R. 1992. Critical Thinking (2nd ed.). Santa Rosa : Foundation for Critical Tthinking.

PAUL, R. 1993. Critical Thinking (3rd. ed.). Santa Rosa : Foundation for Critical Thinking.

PERKINS, D.N. 1986. Thinking Frames. Educational Leadership, 63(8):410, May.

PIAGET, J. 1972. Intellectual Evolution from Adolescence to Adulthood. Human Development, 15:1-12.

REEDER, H.P. 1984. The Nature of Critical Thinking. Informal Logic, 6:1822, Jul.

ROSSOUW, G.J. 1994. Skilful Thinking. Pretoria : HSRC Press.

ROSSOUW, H.W. 1990. Wetenskapsbeoefening as kultuuraktiwiteit. Tydskrif vir Geesteswetenskappe, 30(1):54-65.

SIEGEL, H. 1985. Educating Reason: Critical Thinking, Informal Logic, and the Philosophy of Education, Part Two. Informal Logic, 7(2 \& 3):69-81. 
SIEGEL, H. 1992. Education and the Fostering of Rationality. (In Talaska R.A., ed. Critical Reasoning in Contemporary Culture. Albany : State University of New York Press, p. 89-112.)

STERNBERG, R.J. 1992. Creativity, Critical Reasoning, and the Problem of Content-Oriented Education. (In Talaska R.A., ed. Critical Reasoning in Contemporary Culture. Albany : State University of New York Press. p. 113-131.)

TALASKA, R.A. 1992. Critical Reasoning in Contemporary Culture. Albany : State University of New York Press.

VYGOTSKY, L.S. 1978. Mind in Society. London : Harvard University Press.

WEST, M.A. \& FARR, J.L. 1990. Innovations and Creativity at Work. New York : John Wiley and Sons. 
